\title{
The Assessment of Asbestos Exposure Using Semi-Quantitative Approach and Its Impact on Indonesian Male-Workers' Health
}

\section{Handayani ${ }^{1,2}$, Muchtaruddin Mansyur ${ }^{2}$, Astrid W Sulistomo ${ }^{2}$, and Ricki Marojahan Mulia ${ }^{3}$}

${ }^{1}$ Department of Public Health and Community Medicine, Faculty of Medicine, University of Riau, Indonesia

${ }^{2}$ Department of Community Medicine, Faculty of Medicine, Universitas Indonesia

${ }^{3}$ Secretary of One-Stop Integrated Service Center, Province of Jakarta

\section{Abstract}

Although asbestos has stated as a carcinogen it is still used worldwide in some countries including Indonesia. Very few asbestos studies have been done in Indonesia which underlines the urgency of this study. This study aimed to measure the asbestos exposure among workers using semi-quantitative methods and analyze its impact on

Corresponding Author:

Handayani

dr.handayani.mkk@gmail.com

Received: 26 December 2018 Accepted: 23 February 2019 Published: 7 March 2019

Publishing services provided by Knowledge E

(c) Handayani et al. This article is distributed under the terms of the Creative Commons

Attribution License, which permits unrestricted use and redistribution provided that the original author and source are credited.

Selection and Peer-review under the responsibility of the 2 nd International Meeting of Public Health 2016 Conference Committee.

\section{G OPEN ACCESS} workers' health. This study used a cross-sectional design conducted in a factory which manufactured asbestos-contain materials (ACM) in West Java. We measured asbestos ambient levels at 19 points of workplace unit area representatively. The personal dose was measured for 56 male-workers. These data analyzed by an environmental laboratory. The chest $\mathrm{x}$-ray and spirometry tests were performed by a reputable laboratory. The asbestos ambient levels at 19 points ranged from 0.02 to 0.53 fiber/cc. $36.8 \%$ of these points were higher than asbestos threshold limit value (TLV) 0.1 fiber/cc. The personal asbestos doses among 56 respondents ranged from 0.09 to 1.32 fibers/cc, and $92.9 \%$ of workers had an exposure level which exceeded the TLV. The chest $x$-ray results were standard, while eight workers had restrictive spirometry test results. These workers were susceptible to developing asbestos-related diseases (ARDs) due to a high level of asbestos exposure. Even though the chest x-ray gave standard results currently, the spirometry results had indicated the decrease of pulmonary function among these workers.

Keywords: Asbestos; worker; semi-quantitative; chest x-ray; spirometry

\section{Introduction}

Asbestos is one of the most critical occupational carcinogens, causing about half of the deaths from occupational cancer (ILO and WHO 2007). About 125 million people in the world exposed to asbestos at the workplace years old and it estimated that at least 90,000 people die each year from asbestos-related lung cancer (World Health 
Organization 2006). The International Agency for Research on Cancer (IARC) has stated that all forms of asbestos are carcinogenic to humans (IARC 2012).

Although asbestos use has decreased worldwide through asbestos bans implemented in some countries, use is tending to increase in some developing countries including Indonesia. Asbestos has well known in Indonesia since the 1950s, but there were only three significant studies reported by the Indonesian Ministry of Manpower (Rahayu 2012). Most asbestos studies -including those Indonesian studies- used a quantitative method by measuring the exact dose of asbestos exposure among workers. The quantitative method only shows current exposure doses, while the semi-quantitative method gives more accurate data due to its involving more determinant factors which influence the fluctuation of asbestos exposure. Therefore, we would like to perform the pilot study investigating the asbestos exposure among workers using the semiquantitative method and analyze its impact on workers' health.

\section{Methods}

This study used a cross-sectional design which was modified from previous semiquantitative studies (Singapore Ministry of Manpower n.d.; Wang et al. 2013; Bratveit et al. 2012). The study was performed in a factory that manufactured asbestos-contain materials (ACM) in West Java. We measured asbestos ambient levels at 19 points of workplace unit area representatively. Personal asbestos exposure dose was measured among 56 male-workers; 33 persons came from "B area" which was processing asbestos fibers into sheets, while others came from other unit areas representatively. Each environmental measurement was taken twice in a 4 hour-sampling using flowrate $0.5 \mathrm{~L} / \mathrm{min}$ based on protocols published locally and internationally (Badan Standarisasi Nasional 2004; National Institute for Occupational Safety and Health 1994). The membrane filter was taken from environmental measurement and analyzed at an ecological laboratory. To identify the impact of asbestos exposure, we conducted chest $x$-ray and spirometry examinations which were performed by a reputable health laboratory. Other parameters analyzed with semi-quantitative method were frequency, duration of work handling asbestos and work-behaviors. These measurements were acquired from observation through field visits, while the year of work and workers' age taken from an interview with workers. All numeric data were analyzed using t-test and Mann-Whitney test.

The semi-quantitative method used this formula to assess asbestos exposure among the workers:

$$
E=\frac{F \times D \times M}{W}
$$


Where: $\mathrm{E}=$ weekly exposure (fibers/cc)

$\mathrm{F}=$ frequency of exposure per week

$\mathrm{D}=$ average duration of each exposure (hours)

$M=$ magnitude of exposure (fibers/cc)

$\mathrm{W}=$ average working hours per week (40 hours)

Then,the exposure rating (ER) was calculated by comparing $E$ with asbestos TLV. We categorized ER into 3 groups scales: 1 (low) for less than 0.5, 2 (intermediate) for $>0.5$ to $\leq 1$, and 3 (high) for more than 1 .

\section{Results}

We conducted asbestos ambient level measurement at 19 points of factory areas. The ambient levels ranged from 0.02 to 0.53 fiber/cc. $36.8 \%$ of these points were higher than asbestos threshold limit value (TLV) 0.1 fiber/cc. The five highest ambient levels were found inside "B area" and its surroundings. The lowest asbestos ambient levels found at 2-unit area which located very far away from "B area," i.e., office and "EJ area." Therefore, we classified the unit area into three groups based on the distance of "B area" i.e. high-exposure areas (i.e. "B area", "V area" and "MS area"), intermediate-exposure areas (i.e. "MH area", "MW area", "PTFE area" and "G area") and low-exposure areas (i.e. office, "EJ area", "W area" and security post).

The age of respondents varied; $30.4 \%$ were less than 30 years old, $33.9 \%$ were $30-40$ years old Hassan and the rests were older than 40 years old.

There were 33 respondents from "B area", each 5 respondents from "V area" and "EJ area”, each 2 respondents from "G area”, "MH area”, "WM area”, "PTFE area” and "W area”, each 1 respondent from "MS area", office and security post. The non "B area" workers were selected randomly. The personal asbestos exposure doses among 56 respondents ranged from 0.09 to 1.32 fibers/cc. Most of these workers (92.9\%) had exposure level exceeding the TLV. There was no significant mean comparison on personal exposure dose among these workers.

Based on our calculation for exposure rating based on semi-quantitative formulation, we found that there were $67.9 \%$ of respondents who had high asbestos exposure rate. Meanwhile, the rest had moderate and low asbestos exposure rate $7.1 \%$ and $25 \%$ of respondents, consecutively). The top exposure group consisted of workers came from "B area," "MH area," "MS area" and " $\mathrm{V}$ area." There was no significant difference in mean of personal asbestos exposure dose between high exposure group and low-tointermediate exposure group, neither were for age and length of work. 
We found that all chest $\mathrm{x}$-ray results were within normal, none of these films showed signs of asbestos-related diseases (ARDs). We examined the workers to assess their lung function to find out early objective symptoms of the respiratory system. We found eight workers had restricted spirometry test results.

\section{Discussion}

We reformulated a semi-quantitative method to assess the asbestos exposure size by gathering the formulas taken from Singapore Ministry of Manpower (n.d.), Wang et al. (2013), and Bratveit et al. (2012). The advantage of using semiqualitative method was 1) weighing the flexibility of frequency and duration of asbestos exposure while working rather than one-time measurement, and 2) being implemented more efficiently in assessing occupational risk factors by classifying exposure rate.

In this study, we found that $36.8 \%$ of these points at the workplace exceeded TLV and $67.9 \%$ of respondents had a high asbestos exposure rate. Even though there is no minimum length time of asbestos exposure, we assumed that these respondents had enough exposure since the average of work length was 13 years. Besides, according to Mossman et al., asbestosis may occur after a 10-20 year latency period. We found no asbestosis case among the respondents even though the concentration and duration of exposure fulfilled the prerequisite of asbestosis clinical manifestation. Based on Pathology of Asbestosis guideline released by Asbestosis Committee of the College of American Pathologists and Pulmonary Pathology Society (Roggli et al. 2010), the clinical manifestation also includes the decrease of lung function in an early stage. We found eight workers had restrictive spirometry results.

\section{Conclusions}

Most of the asbestos ambient levels in this factory exceeded TLV, and the personal asbestos exposure dose among workers also showed the same effect. Even though chest $x$-ray abnormalities were not found yet among these workers, the spirometry test indicated that $14.3 \%$ of respondents had restricted lung function. That there were no ARD cases identified among the subjects in this study did not mean these workers were safe from suffering ARDs, as most of them had high asbestos exposure rates. Therefore, further research is needed to elaborate biological markers as an early detection tool to monitor the impact of asbestos exposure to human health before clinical manifestation. It is also recommended to perform a bio molecular study to investigate the role of genetics in susceptibility or resistance to ARDs. 


\section{Acknowledgment}

Authors would like to thank to Directorate of Occupational and Sports Health Indonesian Ministry of Health who sponsored this study.

\section{References}

[1] Badan Standarisasi Nasional. 2004. SNI 16-7059-2004 Pengukuran Statis Kadar Serat Asbes di Udara Tempat Kerja. SNI 16-7059-2004, issued 2004.

[2] Bratveit, M., Bjørg E.H., Kirkeleit, J et al. 2012. Supplementary Information to the Job Exposure Matrix for Benzene, Asbestos and Oil Mist/oil Vapour among Norwegian Offshore Workers. Available from http://www.uib.no/filearchive/supplementaryinformation-to-the-jem-.pdf.

[3] National Institute for Occupational Safety and Health. 1994. Asbestos and other fibers by PCM 7400. Available from https://www.cdc.gov/niosh/docs/2003-154/pdfs/7400. pdf

[4] International Labour Organization and the World Health Organization. 2007. Outline for the Development of National Programmes for Elimination of Asbestos-Related Diseases.

[5] International Agency for Research on Cancer. 2012. IARC Monographs-100C区: Arsenic, Metals, Fibres, and Dust.Vol. 100. Lyon, France. Available from http:// monographs.iarc.fr/ENG/Monographs/vol100C/mono100C.pdf\#page=219.

[6] Kamp, D W. 2009. "Asbestos-Induced Lung Diseases囚: An Update." Translational Research 153 (4). Elsevier Ltd: 143-52. doi:10.1016/j.trsI.2009.01.004.

[7] Ministry of Manpower Singapore. n.d. A Semi-Quantitative Method to Assess Occupational Exposure. Available from https://www.wshc.sg/files/wshc/upload/ cms/file/2014/A-Semiquantitative-Method-to-Assess-Occupational-Exposure-toHarmful-Che.pdf.

[8] Mossman, Brooke T, Arti Shukla, Nicholas H Heintz, Claire F Verschraegen, Anish Thomas, Raffit Hassan, and Raffit Hassanx. 2013. "New Insights into Understanding the Mechanisms, Pathogenesis, and Management of Malignant Mesotheliomas." Am J Pathol 182 (4): 1065-77. doi:10.1016/j.ajpath.2012.12.028.

[9] Rahayu, D. 2012. National Asbestos Profile Indonesia. In The 5th Asian Asbestos Initiative, 1-22. Busan-South Korea. Available from https://www. google.co.id/url?sa=t\&rct=j\&q=\&esrc=s\&source=web\&cd=1\&cad=rja\&uact= 8\&ved=0ahUKEwi54JWi14LQAhWJQo8KHYXPDpAQFggaMAA\&url=http\% 
3A\%2F\%2Fwww.krcard.org\%2Fcommon_english\%2Ffiledown.php\%3Ftid\% 3Dboard_dataroom2012_3\%26ono\%3D10\%26n\%3D1\&usg=AFQjCNFPxeDGm.

[10] Roggli, V L., Gibbs, A R., Attanoos, R et al. 2010. "Pathology of Asbestosis - An Update of the Diagnostic Criteria." Arch Pathol Lab Med 134: 462-80. Available from http://www.amsg.com.au/assets/applets/PathologyOfAsbestosis.pdf.

[11] Wang, S., Wu, T., Juang, Y et al. 2013. "Developing a Semi-Quantitative Occupational Risk Prediction Model for Chemical Exposures and Its Application to a National Chemical Exposure Databank." International Journal of Environmental Research and Public Health 10 (8): 3157-71. doi:10.3390/ijerph10083157.

[12] World Health Organization. 2006. Elimination of Asbestos-Related Diseases. Vol. 1. Geneva: WHO. Available from http://www.who.int/occupational_health/publications/ asbestosrelateddiseases.pdf. 